\title{
SLIDING ROOF MECHANISM FOR LIGHT COMMERCIAL VEHICLES
}

\author{
Ismail Durgun, Hasan Ayartürk, Harun Yeni \\ TOFAŞ-FIAT R\&D Center Bursa / Turkey \\ E-mails: ismail.durgun@tofas.com.tr, hasan.ayarturk@tofas.com.tr, \\ harun.yeni@tofas.com.tr
}

\begin{abstract}
LCV - Light Commercial Vehicles, sliding roof systems have been developed to increase the carrying capacity. In the present application, sliding roof mechanisms are half open and manually rotating mechanism. The sliding roof itself is produced by the SMC method. These applications are very important aerodynamic, water tightness and crash effects for vehicle

In this study, full opens and electric sliding roof with a linear working mechanism has been developed. This sliding roof, by enabling the transport of large objects such as refrigerators, increased load-carrying capacity of the vehicle. Also, using caraskal can be put and taken into the vehicle, which has this sliding roof solution, objects. Moving the outer cover of the sliding roof is made by thermoforming method using continuous glass fibber composite plates. Inner cover of the sliding roof is made by over moulding method using natural fibber composite plates. Functional and leak tests on the prototype vehicles was made for the sliding roof. Functional and water tightness tests on the prototype vehicles was made for the sliding roof. Test results are also presented in this study. Economic and weights analysis was made for developed solution.
\end{abstract}

\section{INTRODUCTION}

Sunroof is applied to benefit more from sunlight, to the vehicle cabin ventilation and aesthetic concerns on the passenger vehicles. This is observed for many different applications (Figure 1). These differences sometimes seen as a form of opening, sometimes applied in different place. When applied on the vehicle, due to bring increased costs, it is generally applied to the upper segment vehicle. Either option is also available to customers in the sub-segment cars. In addition to the cost of implementation sunroof, sound, water intake and to increase the aerodynamic drag caused by technical difficulties are also included. During to designs must be produced solutions these technical problems.
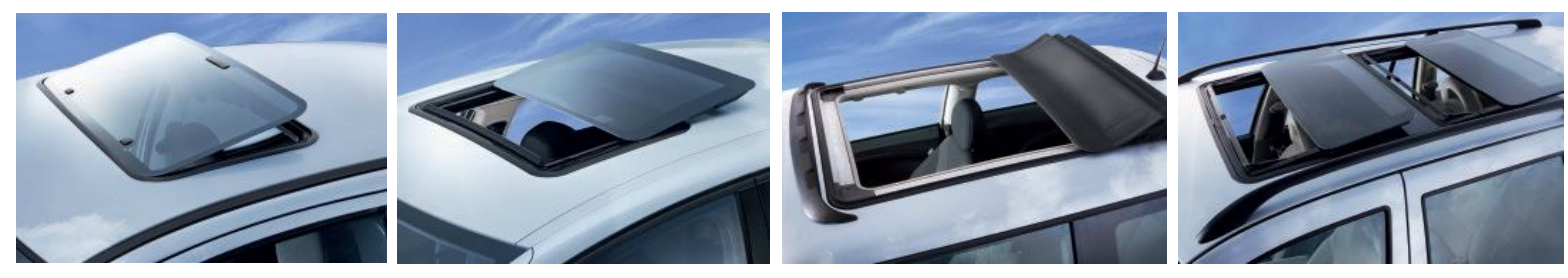

Figure 1. Sunroof applications in passenger car [1] 
There are many different applications to increase the load capacity cargo type commercial vehicles (Figure 2). The load carrying capacity is increased sometimes extending the length of vehicle sometimes increasing the roof height.

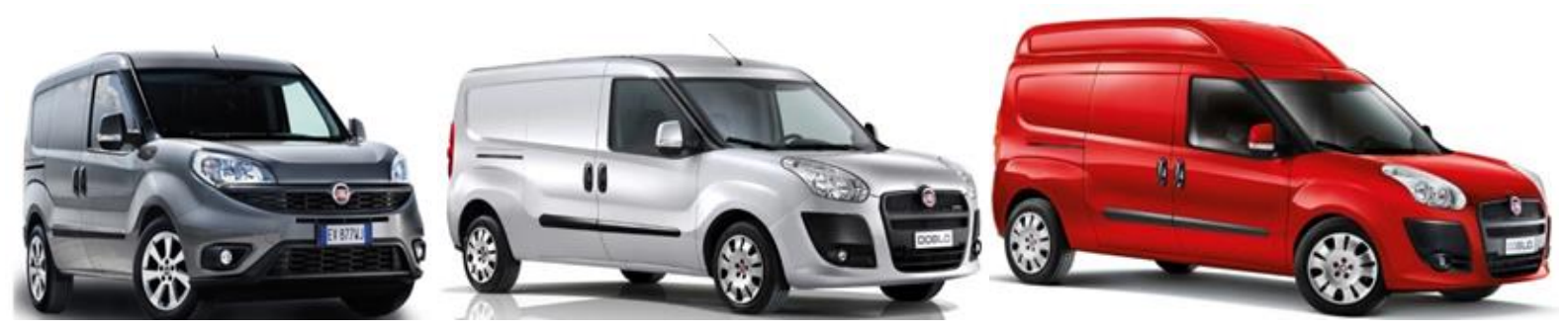

Figure 2. Load capacity increased vehicles [2]

Sometimes, Even if increasing load capacity, as a result of product sizes to be transported, it comes different expectations from customers. For example, It is faced with problems that required to move in a staircase that despite low weight. Some companies have developed applications sunroof to offer this option to their customers (Figure 3). There are no sunroof applications, such as an opens in passenger car due to financial concerns, especially in commercial vehicles. As it can be seen from Figure 3, this sunroof cannot be opened as $90^{\circ}$ due to aerodynamic effects. Therefore, transport can provide a limited increase.

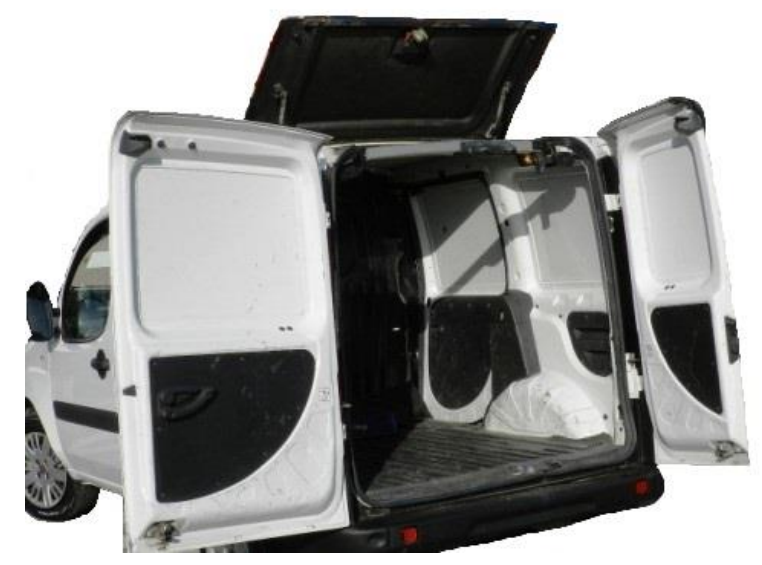

Figure 3. Half opening sunroof applications

\section{GENERAL INFORMATION}

In this study, to increase the load carrying capacity and to improve load a new roof system developed (Figure 4). This is similar to the passenger car applications sunroof is opened parallel to the car roof. 

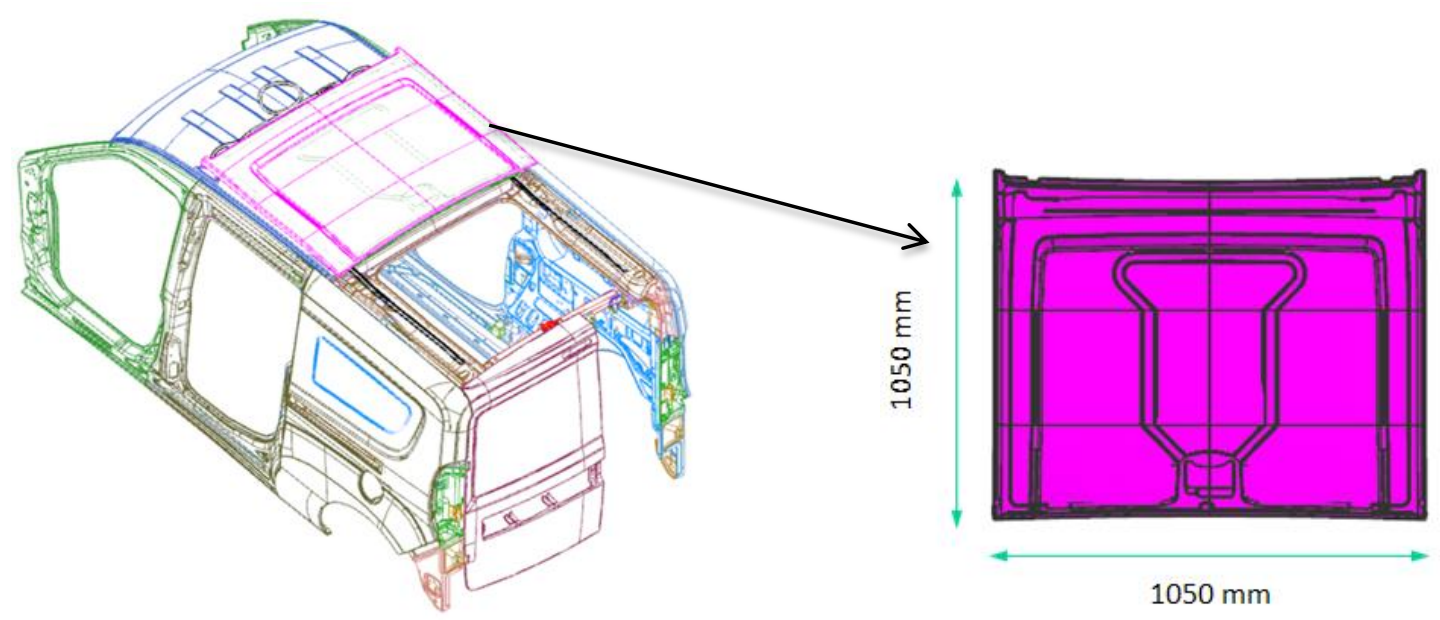

Figure 4. Suggested sliding roof application

In this way sliding roof not only used in the transport of parts such as stairs, it is to allow the transport of all large pieces that section is $1050 \mathrm{~mm} \times 1050 \mathrm{~mm}$ and without height limitations (Figure 5). Again, the smaller pieces of this section can be loaded in a vehicle with a chain hoist. In addition, loading can be done in a vehicle with a forklift due to be opened to traverse the back side of the vehicle
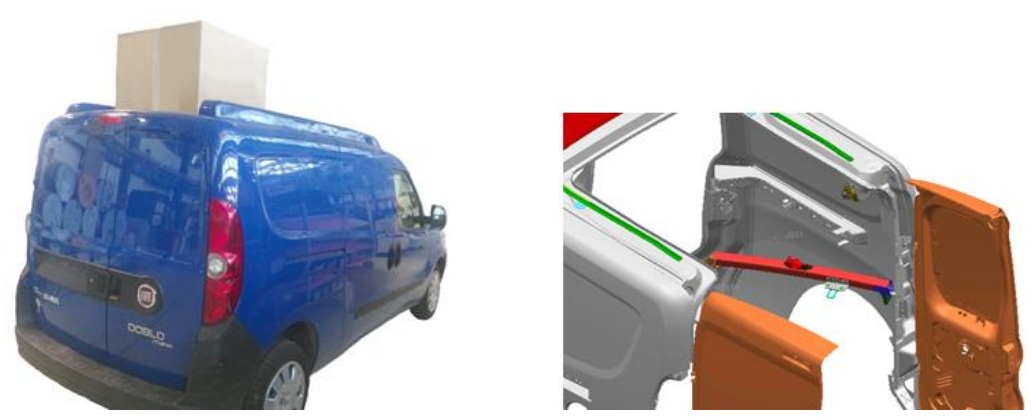

Figure 5. Improvements in loading and transport capacity

It was developed as an electric sliding roof as in luxury passenger cars for increase customer satisfaction (Figure 6). Due to the large size of the opens base, weight reduction activities were made to avoid the difficulties encountered during both the opening and closing. Manufactured parts are used in sliding roof applications usually SMC. Sliding roof is made of natural fiber thermoplastic composite materials.
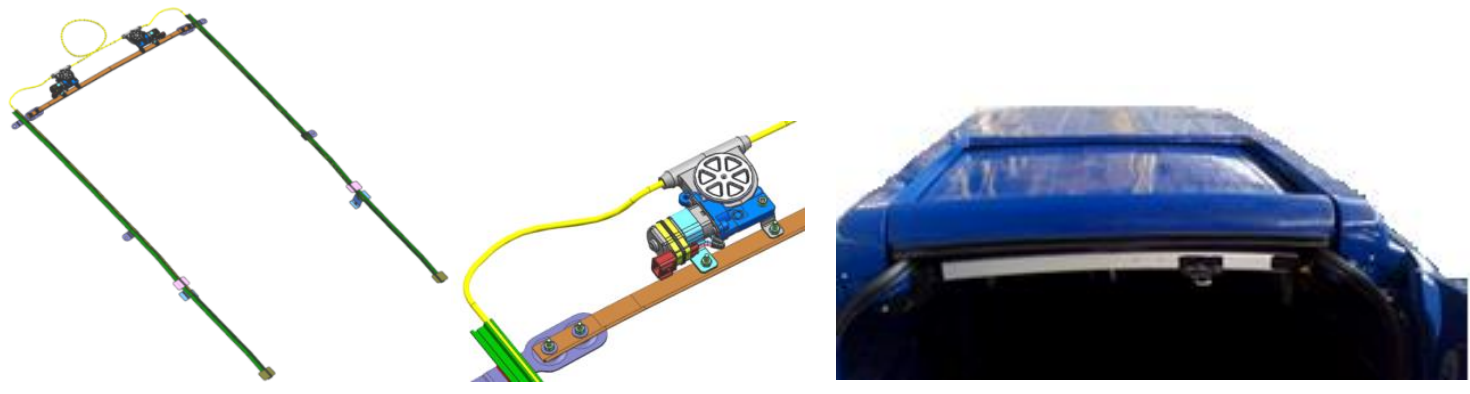

Figure 6. Sliding roof electrical system working 


\section{TESTS}

Due to the absence of similar application, we were asked to complete a questionnaire with our R\&D center employees for to learn how problems may be encountered in the development of the sliding roof and how to eliminate them. We obtained from datas, primarily it was that they should be tested products sealing, noise and wind resistance. It has also been found that should be improved aesthetically as assessed by a customer perspective (Figure 7).

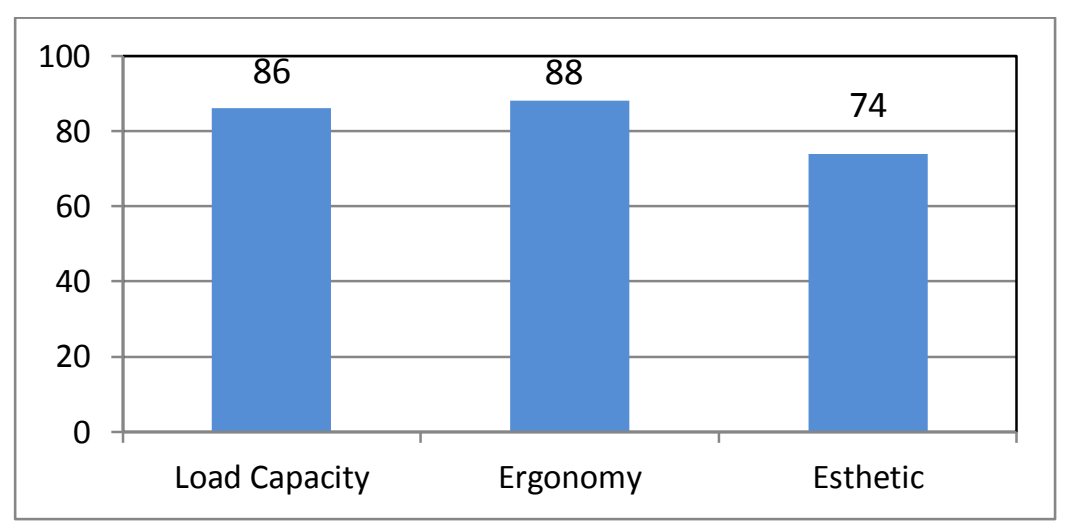

Figure 7. Customer evaluation results

Prototype vehicle were water leaks through the water test cabin that used to control of series production vehicle. The test results have not been encountered in water leakage.

Changes in the level of noise in the vehicle in the process of opening and closing the sliding roof was measured (Figure 8-9). As it can be seen from these measurements made, needs improvement has been seen in some areas. It has been influential in occurrence of this noise from parts also be in the prototype level. But improved with minor changes result from the noise seems to be achieved.
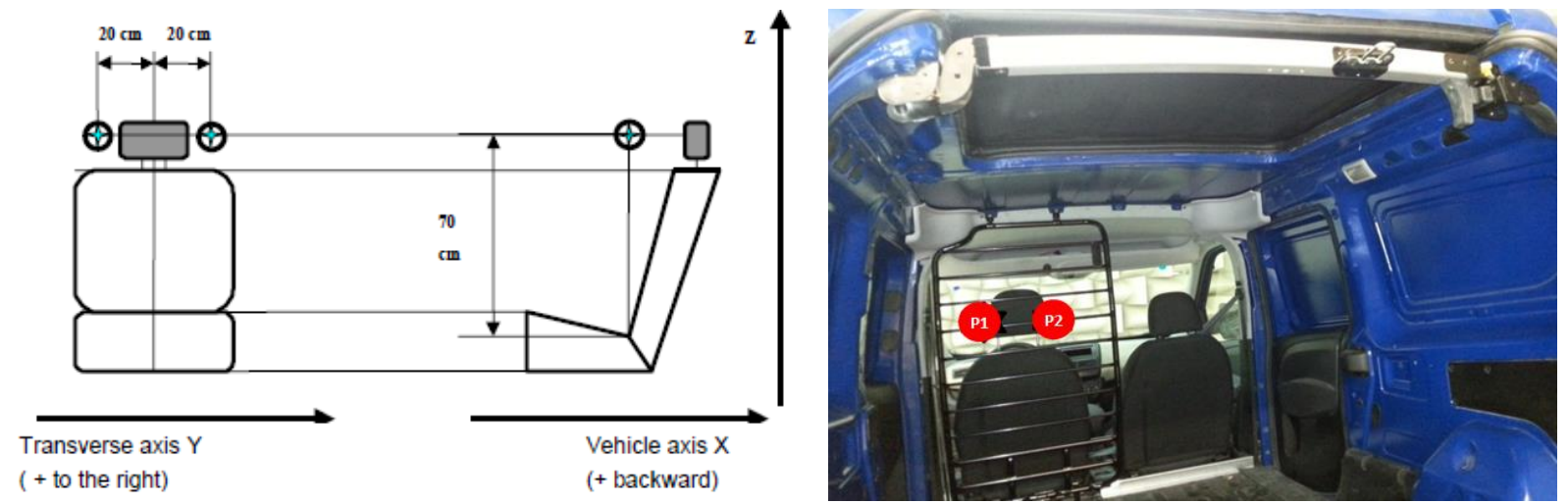

Figure 8. Microphone positions for noise measurements 

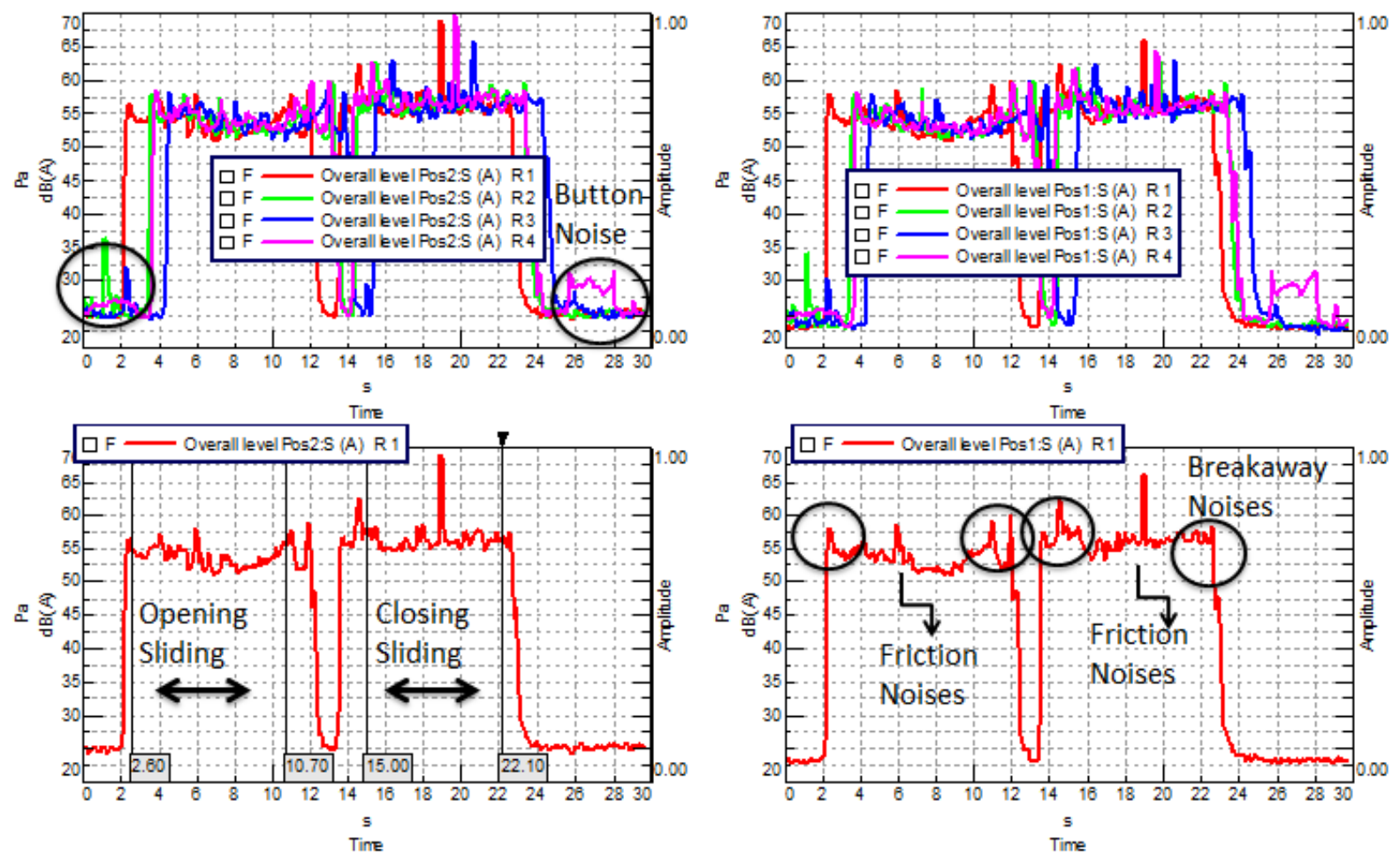

Figure 9. Noise measurements during opening and closing the sliding roof for vehicle

However, loading with forklift and installation attempts made by crane for functional verification of the work performed, it was observed as successful (Figure 10).
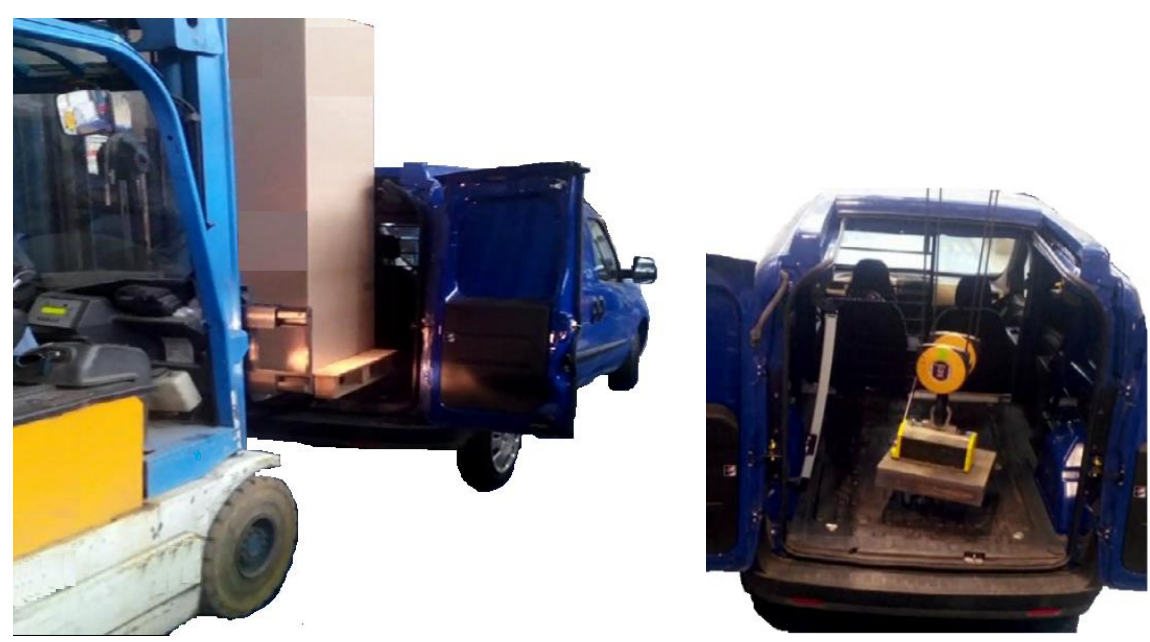

Figure 10. Loading with forklift or crane

\section{CONCLUSION}

Instead of 45 degree turns and half opened roof in commercial vehicles, such as a sunroof can be opened in the passenger car it has been developed. In particular, the transport of white goods such as refrigerators and loading facility was achieved with a forklift. This developed sliding roof has electric automatic opening and closing function, instead of manually opening mechanism 
The tests result, the development of the sliding roof system has been shown to be applicable in commercial vehicles. When provided improvements with additional tests, It is a solution that can be mass-produced with success.

Two patents have been taken for solutions developed during operation $[3,4]$.

Instead of half-opened roof used in the present when these solutions were obtained $4.95 \mathrm{~kg}$ of weight reduction and cost reduction of approximately $28 €$.

\section{REFERENCES}

[1] http://www.webasto.com/fileadmin/webasto files/documents/countryfolder/australia/car/ brochure/australia-car-sunroof-brochure.pdf Accessed on: May 2015

[2] http://www.fiat.com.tr/modeller/sayfalar/YENIDOBLOCARGO/Galeri.aspx Accessed on: May 2015

[3] DEDEOĞLU, Seref; AYDIN, Yusuf. EP 2343206 B1, A Sliding Roof Mechanism For Commercial Vehicles, 2012

[4] AYARTURK, Hasan, DEDEOĞLU, Seref; Yeni, HARUN; ÇETINTTAŞ, Aykut. By Increasing The Load Volume And The Opened Roof Can Be Made Easy Loading And Unloading Mechanism For Commercial Vehicles. Patent, TR2014/14779, 2014 